CREATIVIDAD Y

DRAMATURGIA AUDIOVISUAL

EN TELEVISIÓN ; UN

PROBLEMA DE METODO

\title{
Pedro Gómez
}




\title{
CREATIVIDAD Y DRAMATURGIA AUDIOVISUAL EN TELEVISION: UN PROBLEMA DE MÉTODO
}

Procesos de creatividad errónea en la elaboración de textos primarios para la pequeña pantalla

Por Pedro Gómez

\begin{abstract}
La creciente demanda de ficción televisiva exige una permanente búsqueda en la renovación de argumentos y estructuras. Sin embargo, entre los modelos utilizados para decidir las nuevas directrices del $I+D$ en el ámbito ficcional, destacan los que parten de una concepción exclusivamente basada en la rentabilidad de los resultados más inmediatos. La presión del mercado parece ser la explicación más lógica a dicho fenómeno, que sin embargo niega las condiciones previas a todo proceso de creatividad, negando con ello, lo que dice buscar: soluciones originales a planteamientos nuevos. Bajo la falsa apariencia de un desafío que no llega, las cadenas viven ancladas en el status quo, sin posibilidad de escapar a su obsesiva recuperación de soluciones probadas a planteamientos viejos.
\end{abstract}

En la actualidad, diversos autores del sector de la investigación, la crítica y la interpretación de textos, trabajan en la elaboración de repertorios que intentan establecer una taxonomía de historias posibles, -o más que posibles, probables-, ofreciendo al lector, al investigador y al creador, un catálogo cerrado de argumentos, cuya reiterada frecuencia de aparición en el audiovisual, permitiría hablar hasta cierto punto de una mayor eficacia de ciertas fórmulas narrativas sobre otras. En este contexto, el concepto eficacia ha de entenderse en un doble sentido: tanto por la acogida con que el público preferencia algunos de estos argumentos, como por la insistencia con que los creadores inciden en ellos, con independencia del éxito o del fracaso de sus obras, es decir, su natural tendencia a utilizarlos. 
Las narraciones o historias son, metafóricamente hablando, puentes del entendimiento que nos permiten acceder a realidades sutiles y a veces lejanas, speculo o simulacro del mundo real. Si enunciadores y enunciatarios parecen ponerse de acuerdo en la solvencia de algunas de estas estructuras, cabe reflexionar en la naturaleza de sus elementos constructivos para tratar de definir algunas de sus características y en el futuro, tal vez sus leyes de interacción.

De momento, sólo cabe hablar de un esfuerzo recopilador, pero sorprende que este esfuerzo se haga en unos tiempos en los que la ficción, a través de ciertos medios como la televisión y el cine norteamericano más comercial, se banaliza con sorprendente insistencia. Y frente a este tipo de estudios encontramos dos tendencias: los reduccionistas que consideran vinculable la totalidad de historias posibles a un número de modelos en torno a la veintena (Tobías, Balló, Pérez...) y la de los optimistas, que se niegan a aceptar límites y hablan de una tendencia a la infinutud de historias posibles.

\section{¿La realidad impone límites o abre puertas a la creatividad?}

¿La realidad construye la imagen? ¿La imagen influye en la realidad hasta el punto de que podamos hablar de una construcción de la realidad a partir de la imagen? Desde un punto de vista estrictamente filosófico, Gustavo Bueno (Bueno, 2000) distingue entre una Teoría de la Dictadura de la Audiencia (TDA), una Teoría Ingenua de la Televisión (TIT) y una Teoría Crítica de la Televisión (TCT).

La TDA equivaldría al concepto de "telecracia” impulsado por Pérez Ornia, según el cual, aquello que no forma parte del mundo del público, no puede aparecer en pantalla. Evidentemente algo que no existe en el mundo físico (v. gr. un espíritu, un extraterrestre...) sólo puede ser representado a partir de los atributos físicos que le asignemos (a menudo de forma arbitraria). En el caso de un extraterrestre nos encontraríamos con elementos tomados de la realidad natural (especies vivas conocidas) y asociados libremente por el creador o creativo. Pero además, esta teoría implica la exclusión de hechos o elementos que 
están en el mundo real, pero que por carecer de interés social, no son mostrados en la pantalla.

Las audiencias determinan a través del audímetro qué contenidos son de su agrado y cuáles no $\mathrm{y}$, diversos instrumentos complementarios de medida, permiten (¿potencial o realmente?) detectar elementos "moleculares" que funcionan y otros que que supuestamente no. Por elementos moleculares entendemos microsegmentos de espacio dramático, unidades iconográficas concretas como la presencia/ausencia de determinados actantes, etc... Sobre estos datos, se corrige el producto y se pide al creativo de la televisión (llámese guionista o director, doblegado en todo caso al cada vez más omnímodo poder de los productores ejecutivos) que efectúe las oportunas modificaciones. En definitiva, si los postulados de la TDA fueran correctos sólo cabe hablar de coordinación de contenidos, en menor medida de creatividad ${ }^{1}$.

La TIT nos dice que lo que aparece en la pantalla también está en el mundo. Cabe pensar: ¿qué pasa con el extraterrestre o las criaturas maravillosas que la televisión muestra a veces en los espacios ficcionales? Necesitamos recordar los postulados de Dolezel: "Los mundos ficcionales son conjuntos de estados posibles de cosas"; “[...] son ilimitados en número y gozan de la máxima variedad...”; “[...] puede accederse [a ellos] desde el mundo actual, no físicamente sino a través de canales semióticos...” (Dolezel y otros, 1997). Las relaciones apariencia-verdad en TV estudiadas en estas teorías, parecen limitarse al mundo factual, excluyendo deliberadamente el mundo ficcional, aún cuando cada vez es más difusa la frontera entre lo factual y lo ficcional en el mal llamado "universo televisivo".

La TCT (Adorno y la Escuela de Frankfurt) desde su postura apocalíptica, nos dice que todo cuanto aparece por la telepantalla es apariencia, engaño o mentira. Que la realidad nunca puede ser como nos la muestra la pantalla, parece tan acertado como afirmar que el mundo referencial de la pantalla siempre es el mundo real. Es cierto que los media y no sólo la TV, alteran la realidad por ofrecernos una imagen necesariamente transformada,

\footnotetext{
${ }^{1}$ Entendida en sentido amplio; claro está que muchas de las operaciones efectuadas en el proceso de transustanciación realidad-ficción, intervienen elementos propios de ese constructo psicológico que denominamos creatividad.
} 
restringida y a veces deformada intencionalmente. Y parece plausible que esa deformación a su vez, incida en el mundo real produciendo efectos. Por utilizar una comparación, la relación entre la realidad y el mundo televisivo establecería vínculos parecidos a los que probablemente se darían entre el espejo y la persona que se mira en él. Una iluminación dura, cierta concavidad o convexidad del soporte especular, etc... pueden darnos una imagen alterada de nosotros mismos, que a su vez puede incitarnos a cambiar nuestro aspecto, esto es, a modificar la realidad reflejada en función de la deformación producida por el espejo, dado que a partir de esa imagen el sujeto puede tomar decisiones como hacer régimen si se ve grueso, tomar el sol si se ve pálido, etc...

Pensemos ahora en toda la corte de famosos que abigarran las páginas de las revistas del corazón, pero que también tienen su lugar y no pequeño, en la pantalla televisiva. Famosos que venden su idilio, el escándalo y la separación. Sabemos que existen "pactos secretos", que algunas de esas parejas nunca llegan siquiera a consumar sus relaciones: es un gran negocio. ${ }^{2}$ ¿El espectador sabe que una determinada relación entre famosos está escrita y pactada de ante mano? ¿Sospecha el pacto? ¿Se suma al pacto cumpliendo su parte de creer lo que va a ver? Y en tal caso, ¿son sus expectativas las que deciden el desenlace? ¿Se le da lo que quiere o espera ver? Entonces, una vez más: ¿quién lleva las riendas de la creatividad en la televisión de hoy?

Según la TDA la relación de nuestros dos famosos sería cierta porque la audiencia la asimila como cierta. Según la TIT la relación sería cierta porque si no el medio no se arriesgaría a presentarla como cierta (verdaderamente ingenua esta teoría). La TCT, por el contrario, no aceptaría ningún nivel de verdad en la relación de nuestros dos famosos porque incluso en el caso de que en un principio pudiera ser verdadera, el medio tendería a deformarla hasta el punto de que su evolución iría idefectiblemente encaminada a constituirse sólo en apariencia, estableciéndose distancias cada vez mayores entre el esse y el percipi, entre la verdad y su posibilidad de ser percibida.

\footnotetext{
${ }^{2}$ Esta afirmación no pasa de ser una mera sospecha bastante extendida, por cierto, y que al ser transmitida en estas líneas, podría muy bien integrarse en la realidad aunque no formara parte de ella.
} 
Sin contradecir del todo ninguna de las tres teorías, cabe suponer que realidad y ficción, y a su vez mundo factual y mundo ficcional, tienden a progresar complementariamente a través de la televisión.

En un estudio reciente sobre las series de ficción y sus contenidos, comprobamos sin demasiada sorpresa el profundo parentesco entre las temáticas escogidas y la actualidad de las fechas en las que presumiblemente se llevó a cabo el desarrollo de los guiones. A veces de modo insistente, reiterativo casi, se encontraban menciones explícitas a personajes de la realidad. Otras, se desarrollaban situaciones emparentadas de algún modo con noticias que habían ocupado los sumarios de los informativos en las semanas, apenas meses, inmediatamente anteriores a la fecha de emisión. Sobre un corpus de 30 casos en los que se valoró una distancia de 7-10 semanas entre la escritura y la emisión de los programas, se comprobó que la mayor parte de estas alusiones encontradas se correspondían con hechos que habían sido noticia en la presunta (pero factible) fase de gestación, es decir, el momento del diseño de los contenidos y el guión.

En número insignificante de casos se apreció plena coincidencia temporal entre la noticia y la emisión de la ficción, pero se trataba de noticias previsibles: dos menciones a las olimpiadas y una a un importante partido de fútbol del Campeonato Nacional de Liga.

Ni siquiera formatos aparentemente ajenos a todo realismo, como la sitcom, escapan al contradictorio hambre de realidad y de ficción que demandan nuestras audiencias, a la esquizoide ficcionalización de lo real o realización de lo ficticio. Los popes mediáticos, quienes asumen en el complejo entramado industrial de los medios, la voz de la audiencia, piden a la vez novedades, formatos diferentes, propuestas innovadoras y sin embargo, basta un test de mercado ligeramente desfavorable, para que hagan temblar los cimientos de cualquier proyecto y una vez más exijan, con la misma rotundidad, un continuismo absoluto en la política que debe regir el diseño de los programas de ficción. 


\section{La búsqueda de soluciones creativas}

Así las cosas, cabe suponer que todo el mérito de un creativo, al menos en el encorsetado mundo de la televisión ${ }^{3}$, se restringe a una competencialidad limitada a ciertas capacidades para saber construir un equivalente del mundo real que sepa empatizar con la audiencia. La etapa de preparación (Baños, 1999), en la que se decide qué se va a producir, corresponde a los poderes ejecutivos de las estaciones. Es la fase en la que se detecta la ausencia de una determinada temática en la programación, el alto interés suscitado por una problemática concreta o simplemente el momento en el que se toma la decisión meramente comercial, de captar una determinada franja de edad que atrae la publicidad de importantes firmas.

Bastaría una simple encuesta entre los guionistas (y posiblemente realizadores) de programas de ficción, para comprobar el palpable descontento mutuo entre creativos y productores, tal vez alimentado por la genérica incomprensión entre unos y otros, en la que todo hay que decirlo, las cadenas y los productores no favorecen casi nunca las condiciones que más potencian la creatividad, enunciadas por Rogers (aceptación del individuo, ausencia de prejuicios en la valoración de su trabajo, etc...) (en Baños, 1999).

En las etapas de incubación e iluminación se produce la tradicional diáspora de guionistas, directores y realizadores, según se van viendo los primeros resultados del proyecto. Ceses, nombramientos, más ceses y más nombramientos culminan en el piloto, que casi siempre suele terminar en el cubo de la basura ${ }^{4}$. El método del brainstorming es en la actualidad el más aludido en estas dos etapas, aunque como veremos más adelante, el brainstorming utilizado en la realidad, guarda sólo algunos elementos comunes con el método propuesto por Osborn..

La etapa de verificación llega con los primeros test de mercado y supone casi siempre el fin de cualquier fermento creativo, si es que en algún momento pudo fermentar nada que tenga que ver ni de lejos con la creatividad. Si hay suerte, la serie será emitida teniéndose

\footnotetext{
${ }^{3}$ Parangonable desde luego al del cine más comercial.

${ }^{4}$ Esta práctica, tomada del modelo americano, era impensable apenas hace algunos años. Hoy, con relativa frecuencia, se abandonan los proyectos una vez que se comprueba que el "concepto" no funciona como se esperaba.
} 
en cuenta las aportaciones de la audiencia sugeridas en las cualitativas (grupos de discusión, principalmente). Si el éxito viene a recompensarnos, tendremos una serie que será criticada hasta el hartazgo por un porcentaje suficiente de espectadores que no podrá ser inferior al 20\% en términos de share. Lo importante es que la vean, aunque hablen mal: si hay disfrute o simple desahogo en el consumo del producto, carece de relevancia.

Aún durante su efímera vida, las series siguen sufriendo continuas modificaciones. En los gabinetes de ficción se decide qué personajes deben liarse, morir, quedar tullidos, emprender largos viajes, regresar, etc... En nuestros trabajos de investigación hemos denominado a algunas de estas acciones funciones resolutivas, por ser las que desencadenan el final de un personaje en la serie. El término función, aunque con matizaciones, está inspirado en las investigaciones de Vladimir Propp ${ }^{5}$. La importancia de las funciones tiene mucho que ver con la posibilidad de ejercer una cierta creatividad en un entorno regido ante todo por la viabilidad comercial de los proyectos. Porque si la dinámica oficial, como aquí ha sido descrita, ofrece a la audiencia lo que supuestamente quiere ver, es competencia exclusiva del creativo decidir los modos de operación conducentes a ese resultado. El consumidor expresa su gusto, demasiado dulce, demasiado salado. El especialista establece la fórmula.

En cada segmento de texto predomina una función: engaño, ruego, mandato, etc... y hay multiples variables en el manejo de las mismas que pueden alterar su resultado final. Entre ellas, destacamos:

Cantidad.- Cuando en una secuencia o fragmento se dan muchas funciones diferentes, la acción es percibida en términos generales y a igualdad de otros factores, con mayor ritmo que si el mismo periodo gira en torno a una única función.

Longitud.- En relación a lo anterior, los segmentos funcionales demasiado extensos tienden a frustrar el interés de los espectadores. Su longitud excesivamente breve, por el

\footnotetext{
${ }^{5}$ Propp calculó 31 funciones que involucran al héroe(pueden involucrar a los otros personajes cuyo repertorio según el autor y en lo que se refiere al cuento tradicional estaría compuesto por las figuras del agresor, la víctima, el héroe, el donante, el guía, el falso héroe y el persecutor.
} 
contrario, puede generar problemas de decodificación que incidirían en una mala valoración global del texto. Su longitud por tanto deberá ajustarse a la intensidad dramática de la función, a su importancia cualitativa dentro del texto y guardará una relación proporcional adecuada al tamaño del episodio.

Pertinencia.- No todas las funciones encajan con todos los personajes. El público rechaza asignaciones funcionales incorrectas o que contradigan la etiqueta semántica del personaje, salvo que le sean proporcionadas claves justificadoras adecuadas, en cuyo caso el "giro" del personaje podrá ser aceptado.

Calidad de construcción.- Si los segmentos funcionales no presentan la información de manera concisa sino que lo hacen de forma difusa, el enunciatario tiende a no captar la intención del texto y a percibir como sobrante el segmento (en palabras de Hitchcock: "lo que no suma, resta"). Otros factores ajenos a la dramaturgia, como la correcta ejecución de los intérpretes, pueden incidir en el resultado valorativo final.

Tono.- El tratamiento cómico-serio predominante en el segmento será aceptado/rechazado dependiendo de su adecuación al tipo de trama (cómica-seria) en la que se integre. Por lo general, las audiencias no aceptan de buen grado los cambios de tono dentro de un mismo segmento funcional.

Estos cinco puntos se han diseñado a partir de algunos estudios previos con muestra accesible (de conveniencia) y sólo nos permiten hablar de tendencias probables. En ningún caso de leyes y ni tan siquiera, de modelos estables de explicación.

Tal y como reconoce García García $(1984,42)$, la creatividad ha de juzgarse tanto en el producto final como en el proceso, siendo esenciales su novedad y su utilidad. Las exigencias de resultados creativos por parte de las cadenas, chocan diariamente en televisión, con las limitaciones de un orden mediático que restringe las novedades a una supuesta aceptación telecrática de los públicos mayoritarios (si atendemos a las posturas de la TDA) o a las imposiciones de quienes se toman el trabajo de pensar y decidir por la 
audiencia, elevando al altar icónico sólo aquellos elementos que interesan al tejido social. Triste victoria la de un espacio dramático que surge de ese impulso masivo y que sobrevive sólo gracias a él.

\section{¿Creatividad o replicabilidad?}

La relación palpable entre la creatividad y lo que se ha dado en llamar inteligencia emocional (Goleman y otros autores), sienta a nuestro entender, un contrapunto interesante, que contradice ciertas posturas sostenidas en las "políticas de producción" de la mayor parte de las cadenas generalistas. Las investigaciones de Ledoux y Damasio demuestran por primera vez la existencia de unas vías nerviosas específicas para los sentimientos, que eluden el neocórtex. Tal recorrido nos sugiere el poder desbordador de las emociones frente a la razón, puesto que se trata de un camino directo hasta la amígdala, de un origen más intenso y primitivo (anteriormente, Ledoux ya había demostrado el papel de la amígdala como centinela emocional). En otros experimentos se ha demostrado que la inteligencia intrapersonal (emocional) favorece la comprensión y el trabajo con uno mismo (Puente Ferreras, 1999), mientras la inteligencia interpersonal favorece el trabajo con los demás. Esto es lo que nos dice la ciencia y sin embargo, no es lo que potencia la industria.

Antes hemos aludido al brainstorming como el método creativo más reconocido por la mayor parte de los profesionales que se encargan de confeccionar los contenidos ficcionales televisivos. Es este el momento de aclarar, que el método en realidad practicado, es un híbrido de otros muchos y que sólo vagamente guarda relación con el brainstorming, al menos tal y como lo concibió su creador, Alex Osborn. Veamos por qué.

En primer lugar, la definición del problema no suele ser concreta, ni rigurosa. Es mucho más frecuente partir de la nada. El paso siguiente consiste en que los "clientes" que por supuesto no intervinieron en la reunión, se dedicarán a torpedear cuanto se haya gestado en la sesión de trabajo, pero casi nunca (y no es exagerado el adverbio) hay un criterio concreto en esas críticas. Si lo hay es improvisado a posteriori con relación a la convocatoria de la reunión y a los resultados de la misma, pero en general domina la ausencia de directrices claras, lo que no debe entenderse como una invitación a la libertad 
pensante, sino como una auténtica dictadura de la más burda ineficacia para "crear". En segundo lugar, jamás (y perdón de nuevo por la rotundidad), se establece un límite temporal para las sesiones, lo que se traduce en continuas pérdidas de tiempo (si los guionistas usaran taxímetro...) Queda en manos de la habilidad particular del director de la reunión establecer el grado de oportunidad de las distintas intervenciones, pero en general se tiende a evaluar sobre la marcha y no después de haberse depositado la última idea, como aconseja el método en su versión ortodoxa. En ocasiones se potencia el pensamiento metafórico y algunas otras técnicas coincidentes con la llamada sinéctica de William Gordon.

\section{De nuevo "realidad" versus "ficción"}

La dialéctica realidad - ficción con la que iniciábamos este artículo, se torna ahora en insoslayable pugna entre política restrictiva y clónica de las estaciones o verdadera búsqueda de soluciones creativas. De la tensión entre la aparente "racionalización" de los riesgos, y el motor siempre impredecible de la creatividad, surgen los programas que consumimos. Pero en casi todos los casos (por no hablar de una total ausencia de excepciones), el conflicto se resuelve a favor del orden y en contra del caos. Si se quiere, la razón predomina frente a inteligencia emocional. Pero la razón es sierva de la lógica del mundo real, lo que explica en parte tan intensa proximidad entre realidad y ficción.

Si como dice Bueno, las audiencias tienen lo que se merecen, cabe al menos preguntarse qué lado del cerebro de la audiencia trabaja más intensamente, cuando la mano sostiene el mando a distancia (o si trabaja realmente alguna parte del cerebro en ese acto de visionado y perdón ahora por la ironía). Si el espectador busca sólo notas del mundo real y admite sólo la lógica del mundo real, llevan razón los que no aceptan el mínimo exceso en el acto de la creatividad. Si por el contrario es cierta (y no mera fachada) la postura crítica de un cada vez más amplio- sector de las audiencias, que demanda verdaderas novedades en el ámbito de la ficción televisiva, entonces, ¿en qué lugar quedan los “intermediarios restrictivos"? 


\section{BIBLIOGRAFIA}

BAÑOS, M (1999) Métodos heurísticos y creación publicitaria. Tesis doctoral. UCM.

BUENO, G (2000) Televisión: apariencia y verdad Gedisa. Barcelona

DOLEZEL, L y otros (1996) El texto narrativo. Síntesis. Madrid.

GARCIA GARCIA, F. (1981) Creatividad e Imagen en los niños. Servicio de publicaciones del MED.

Madrid.

GOLEMAN, D. (1997) Inteligencia emocional. Kairós. Barcelona.

GOLEMAN, D. (1999) La práctica de la inteligencia emocional. Kairós. Barcelona.

PROPP, V. (1992) Morfología del cuento (8a edición) Fundamentos. Madrid.

PROPP, V. (1998) Las raíces históricas del cuento (6 edición). Fundamentos. Madrid.

PUENTE FERRERAS, A. (1999) El cerebro creador. Alianza editorial. Madrid. 